\section{Case Reports in Orthopedic Research}

\title{
A Very Rare Fracture: Isolated Fresh Lunate Fracture
}

\author{
Bulent Karslioglu Ahmet Keskin Olcayto Ocak Yunus Imren \\ Suleyman Semih Dedeoglu \\ Department of Orthopedics and Traumatology, HSU Prof. Cemil Tascioglu City Hospital, \\ Istanbul, Turkey
}

\author{
Keywords \\ Isolated $\cdot$ Lunate $\cdot$ Fracture
}

\begin{abstract}
Lunate fractures are rare and usually occur together with other fractures, dislocations, or ligament disruptions. We want to report an acute fresh isolated lunate fracture without additional ligamentous injury fixated with early surgical intervention. A 23-year-old right-handdominated male patient was admitted to our hospital after falling from 1.5-meter ladder over right hand's palmar face. Standard radiographs diagnosed a displaced lunate fracture. In the intraoperative evaluation, it was observed that there was only lunate dislocation, and there was no ligament lesion or other carpal bone pathology. Fracture was fixed with a headless cannulated screw. Radiographs showed bony union at 6-week follow-up. There was no evidence for Kienböck's disease 6 months after surgery. Case report regarding fresh isolated lunate fracture that results in clinical success with early intervention without developing avascular necrosis as in our report is extremely rare. In conclusion, satisfying results can be obtained in these patients with careful surgical intervention.
\end{abstract}

\section{Introduction}

Hand fractures are most common upper extremity fractures and account for about $\% 18$ of all fractures. Carpal fractures comprise $8 \%$ of all hand fractures [1]. Lunate fractures are uncommon carpal fracture which accounts for $0.5-6.5 \%$ of all carpal fractures [2]. Lunate fractures are usually accompanied with other carpal fractures, perilunate dislocations, or ligament disruptions since it is usually caused by high-energy traumas. 
Sometimes lunate fractures can be overlooked. As a result of the persistent pain and continued limitation in wrist movements, these patients can often be diagnosed lately. If patients are untreated, Kienböck's disease may develop in the future [3]. Case report regarding acute isolated lunate fracture is extremely rare [4]. We want to report an acute fresh isolated lunate fracture fixated with early surgical intervention without additional ligamentous injury.

\section{Case}

A 23-year-old male patient was admitted to our emergency orthopedics clinic with complaining of fall from 1.5-m ladder over right hand's palmar face. There was a tenderness on palpation of dorsal surface. The patient had severe pain, and range of wrist movements was restricted. The right wrist flexion was $55^{\circ}$, but extension was $30^{\circ}$ and painful. Radioulnar deviation was also painful. There was no pain on the anatomic snuffbox which is important for differential diagnosis for scaphoid fracture. However, middle side of dorsal wrist was very painful with palpation. Reagan's ballottement test was performed to detect possible lunotriquetral ligament rupture and Watson test were performed to figure out scapholunate instability. Both tests were negative.

Standard posteroanterior and lateral radiographs of affected wrist diagnosed a linear fracture line especially more obvious at lateral X-ray (Fig. 1a), but we did not find any evidence to suggest a ligament lesion like break at Gilula's line or Terry-Thomas sign. The palmar displaced lunate fragment was noted. Computed tomography scan confirmed the diagnosis (Fig. 1b) and showed no other accompanying bone injuries. No other disorder was observed. A short arm plaster splint was applied and the patient was operated on the same day.

A volar 3-4 cm longitudinal incision in line with the middle ray was made. Retinaculum and the flexors were exposed, and they were retracted laterally. The radio lunate gap was marked with the aid of an injector tip and confirmed by scopy (Fig. 2a). The capsule was incised, and the lunate fracture was directly visualized. The scapholunate and lunotriquetral ligaments also were directly visualized, and they were found to be

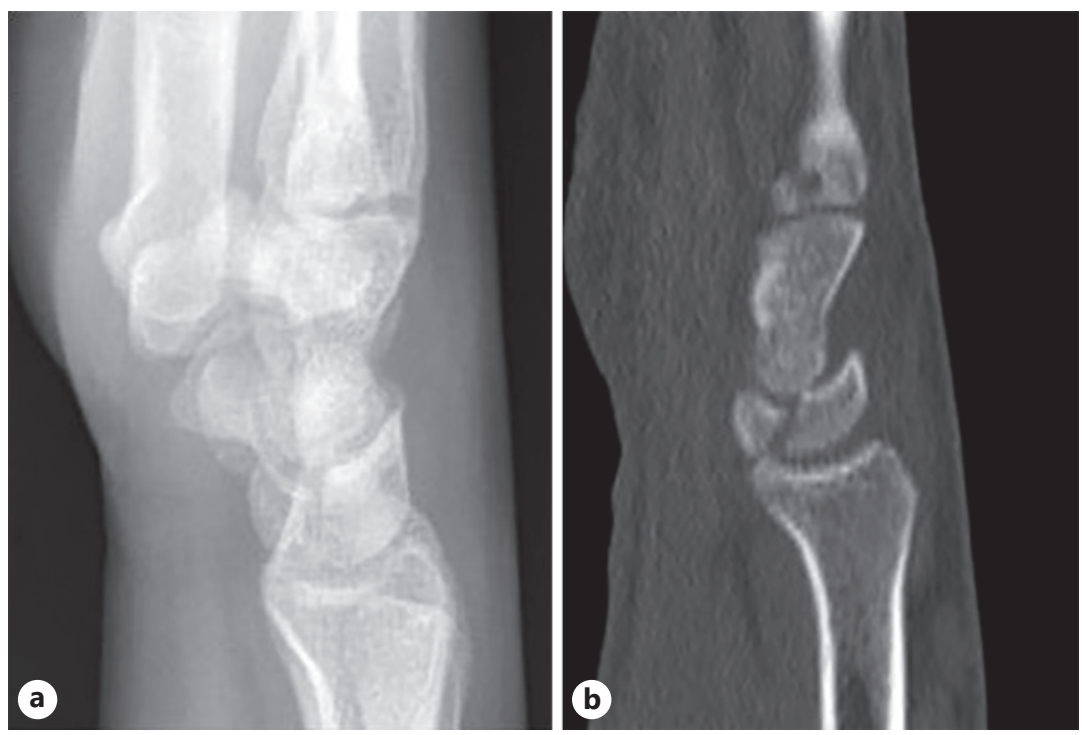

Fig. 1. Preoperative lateral radiograph (a) and lateral CT scan (b). CT, computed tomography.

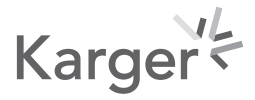


Case Reports in Orthopedic Research
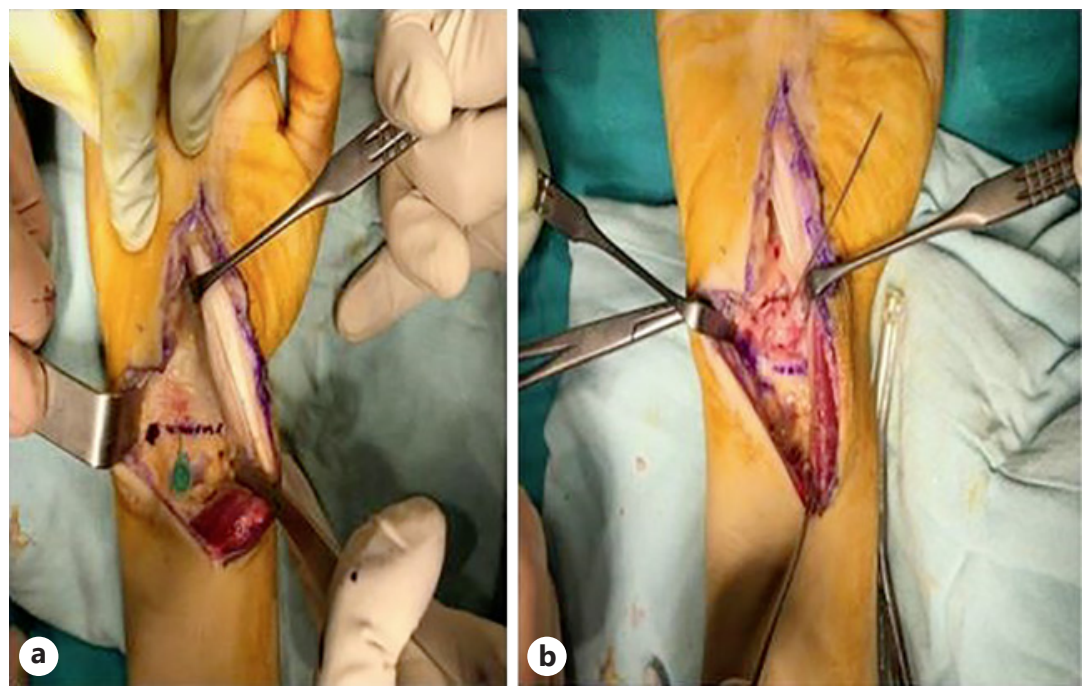

Fig. 2. a The radio lunate gap was marked with the aid of an injector tip. b Scapholunate and lunotriquetral ligaments were found to be intact.
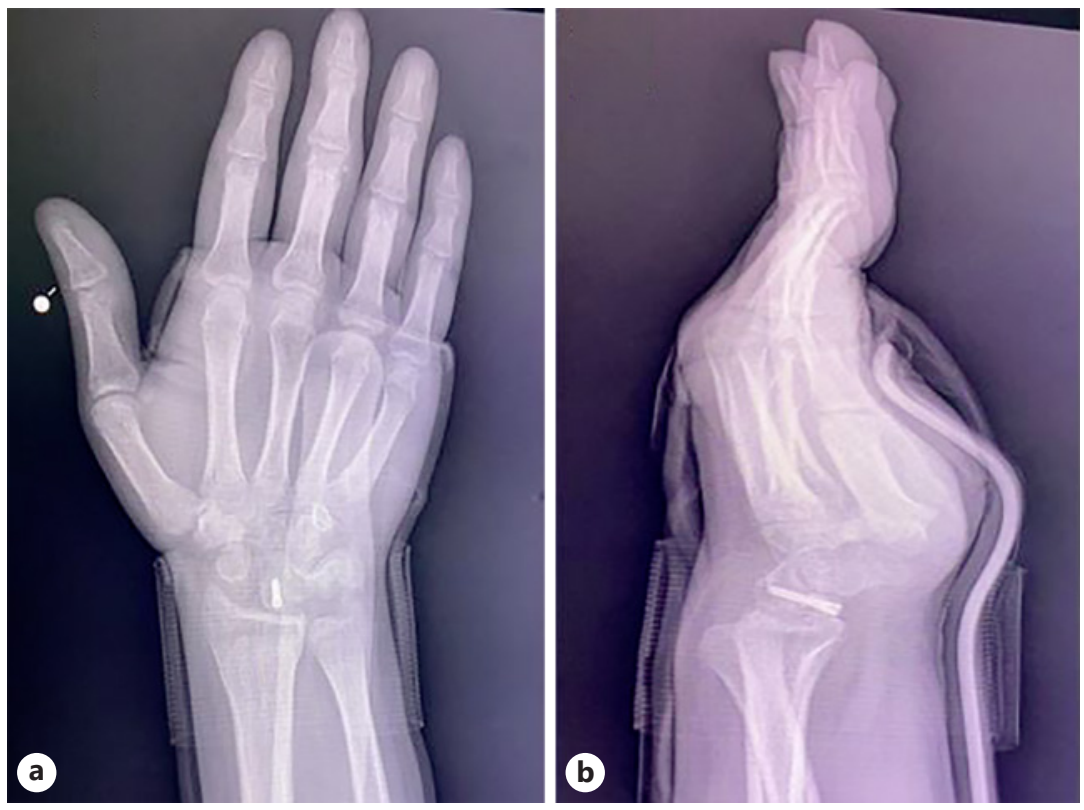

Fig. 3. Postoperative AP (a) and lateral radiographs (b).

intact with no evidence of tears (Fig. 2b). After achieving good reduction fracture was fixed with a headless cannulated screw (Fig. 3). The surgery was terminated by applying a splint.

Radiographs showed good bony union and splint were removed at 6-week follow-up. The patient was encouraged to act to increase the range of motion of the wrist as the pain allowed. Wrist flexion was $55^{\circ}$ and extension $50^{\circ}$, and patient had no pain at 3-month follow-up. Patient was followed for 6 months if there was any evidence for Kienböck's disease. No radiological appearance or clinical examination findings suggestive of Kienböck's disease were found. 
Case Reports in Orthopedic Research

\begin{tabular}{l|l}
\hline Case Rep Orthop Res 2021:4:79-83 \\
\hline DOI: 10.1159/000515812 & $\begin{array}{l}\text { @ 2021 The Author(s). Published by S. Karger AG, Basel } \\
\text { www.karger.com/cio }\end{array}$ \\
\hline
\end{tabular}

Karslioglu et al.: Isolated Lunate Fracture

\section{Discussion}

The incidence for isolated lunate fracture is very low. Fracture typically occurs together with other carpal fractures, perilunate dislocations, or ligament disruptions. Closed treatment with prolonged cast immobilization for 6 weeks for undisplaced lunate fractures is the recommended form of treatment [5]. Early surgical intervention with $\mathrm{K}$ wire or screws after good anatomical reduction reduces the risk of developing osteonecrosis in displaced lunate fractures [5].

The energy that reveals the fracture passes through the dorsiflexion and the wrist in the ulnar deviation and was transferred from the capitate bone to the lunate bone [6]. Mayfield et al. [7] made a cadaveric study and showed that slower application of the load to the bone was more likely produce fracture before damaging surrounding soft tissue damage. These kinds of injuries are called as greater arc injuries. Rapid application of the load leads to ligamentous disruptions, and they are called as lesser arc injuries [7].

Teisen and Hjarbaek classified lunate fractures in their radiographic review of 17 cases. Their classification system consists of 5 groups formed according to the radiological appearance of the fracture: group I, volar pole fracture which affects volar nutrient artery (most common); group II, chip fractures which do not affect any vascularity; group III, dorsal pole fractures which affect dorsal nutrient artery; group IV, sagittal fractures through the body; and group V, transverse fractures through the body of the lunate [8].

Vascular anatomy of the lunate bone is important for the development of Kienböck's disease. Gelberman and his friends showed that blood supply is less at proximal radial aspect of the lunate bone [9]. The time of surgery, history of smoking, or other problems together with the anatomical location of the fracture which disrupt microcirculation are effective in the development of avascular necrosis. In our case report, our patient had a group 1 displaced volar pole fracture. Although there is a high risk of developing avascular necrosis, due to our early surgical intervention and the patient nonsmoking manner, Kienböck's disease was not observed at the end of 6 months.

The lunate bone has the largest cartilage surface area among all other carpal bones for that reason has the lowest nerve support $[2,8]$. Patients may not have evident pain except for displaced fractures because separation of the periosteum causes clinically significant pain. Fracture may be overlooked in patients for whom radiological examination is not required due to soft tissue injury. The diagnosis could be made with radiological examinations performed on suspicion due to the pain and edema in our patient.

Case report regarding fresh isolated lunate fracture that results in clinical success with early intervention without developing avascular necrosis as in our report is extremely rare [4]. In conclusion, satisfying surgical results can be obtained in these patients with careful surgical intervention.

\section{Statement of Ethics}

Ethical approval: the study was approved by the Institutional Review Board of Okmeydani Training and Research Hospital.

Informed consent: written informed consent was obtained from the patient for publication of this case report and any accompanying images.

\section{Karger'}




\section{Case Reports in Orthopedic Research}

\begin{tabular}{l|l}
\hline Case Rep Orthop Res 2021:4:79-83 \\
\hline DOI: 10.1159/000515812 & $\begin{array}{l}\text { @ 2021 The Author(s). Published by S. Karger AG, Basel } \\
\text { www.karger.com/cio }\end{array}$ \\
\hline
\end{tabular}

Karslioglu et al.: Isolated Lunate Fracture

\section{Conflict of Interest Statement}

Authors, their immediate family, and any research foundation with which they are affiliated did not receive any financial payments or other benefits from any commercial entity related to the subject of this article. The authors declare that they have no conflicts of interest.

\section{Author Contributions}

Bulent Karslioglu: writing and conceptualization. Ahmet Keskin: visualization and investigation. Olcayto Ocak: data curation. Yunus Imren: reviewing. Suleyman Semih Dedeoglu: reviewing.

\section{References}

1 Van Onselen EB, Karim RB, Hage JJ, Ritt MJ. Prevalence and distribution of hand fractures. J Hand Surg Br. 2003; 28(5):491-5.

2 Hsu AR, Hsu PA. Unusual case of isolated lunate fracture without ligamentous injury. Orthopedics. 2011; 34(11):e785-9.

3 Raghupathi AK, Kumar P. Nonscaphoid carpal injuries: incidence and associated injuries. J Orthop. 2014; 11(2):91-5.

4 Raval P, Patil P, Singh S. Surgical treatment of an isolated fresh lunate fracture. Case report of a rare injury and review of literature. SN Compr Clin Med. 2020;2(9):1697-701.

5 Shunmugam M, Phadnis J, Watts A, Bain GI. Lunate fractures and associated radiocarpal and midcarpal instabilities: a systematic review. J Hand Surg Eur Vol. 2018;43(1):84-92.

6 Guo W, Yuan B, Zhu Z, Huang C, Li R, Wu D. Non-dislocation lunate fracture combined with distal radius fracture: a case report. Medicine. 2018;97:e13574.

7 Mayfield JK, Johnson RP, Kilcoyne RK. Carpal dislocations: pathomechanics and progressive perilunar instability. J Hand Surg Am. 1980;5(3):226-41.

8 Teisen H, Hjarbaek J. Classification of fresh fractures of the lunate. J Hand Surg Br. 1988;13(4):458-62.

9 Gelberman RH, Bauman TD, Menon J, Akeson WH. The vascularity of the lunate bone and Kienböck's disease. J Hand Surg Am. 1980;5(3):272-8.

\section{Karger' ${ }^{\prime}$}

